\title{
Microscopic Virtual Media (MVM) in Physics Learning to Build a Scientific Conception and Reduce Misconceptions: A Case Study on Students' Understanding of the Thermal Expansion of Solids
}

\author{
F. C. Wibowo, A. Suhandi, D. Rusdiana, Y. Ruhiyat, D. R. Darman \\ Universitas Pendidikan Indonesia \\ Bandung, Indonesia \\ firmanu127@gmail.com
}

\begin{abstract}
A domain of research in physics teaching is focused on the study of the effects of different types of learning interventions aimed to help students build a scientific conception. Microscopic Virtual Media (MVM) is the application of a particular interest in physics learning because they can support microscopic powerful modeling involving physics concepts and processes. In this study, one group (experimental) of 19-20 year old students were studied to determine the MVM role in the development of a functional understanding of the concept of expansion of solids. The experimental group used MVM using DLSM (Dual Situated Learning Model). The results presented here indicate that students work with virtual media exhibited significantly higher scores in research tasks. Our findings strongly support that MVM can be used as an alternative instructional tool, in order to help students reduce their scientific misconceptions and develop an understanding of physics concepts.
\end{abstract}

Keywords-Microscopic Virtual Media (MVM), Dual Situated Learning Model (DLSM), Scientific Conception, Misconceptions

\section{INTRODUCTION}

Success in learning physics is determined by one's own understanding of the concept, because physics is a collection of concepts, which is extracted from natural phenomena that arise from events that occur in everyday life. Facts about natural phenomena are investigated and tested through repeated experiments, and then based on the results of experiments the theory is formulated.

The universe is an integral part of the system that cannot be separated. The universe as a whole must be studied because knowledge of human nature will add strength to overcome the problems. Humans have a curiosity about the nature of Natural Sciences itself. The purpose of finding out is realized in the form of asking and thinking systematically, so that the Natural Sciences is not just curiosity or mastery of knowledge in the form of a collection of facts, concepts, or principles but also a process of discovery [1].

Physics is part of the Natural Sciences that finds out about the natural sciences which is expected to become a vehicle for students to learn about themselves and the nature around. Learning Physics emphasizes in providing direct experience to develop the competence of learners to be able to explore and understand the universe around scientifically. Constructive learning of science is as a dynamic process of building, organizing, and elaborating knowledge of natural word [2].

The results of its investigations related to the use of virtual media in learning physics are oriented to the construction and reconstruction of conception. The research results [21], [22] showed that the use of virtual media can change the conception of learners who have misconceptions through restructuring concept in depth. Research results [23] showed that the use of simulation media on climate change materials facilitates construction of the transformation in the conception in the minds of learners; Research results [18] and Kaewkhong [24] show that learning with media simulation can reduce the quantity of student misconceptions in optical materials. Learning physics simulation that uses electric magnetic media can change the conception of a student who is not scientific to the scientific conception [26]. [25] showed that the use of media simulation of light and color dispersion is effective in helping students to construct its conception so that the ability to understand can be improved; [19] showed that the use of virtual simulation media on the concept of light waves could improve understanding of the concept of waves and the process of changing the conception (Conceptual Change) students towards scientific conception.

Some virtual media related teaching materials have been developed partly physics at the University of Collorado PhET Simulation in the form can be accessed and downloaded for free by the public. Virtual media developed has been widely used by teachers of physics, including in Indonesian educational institutions at the secondary school level to the college level. However, not all virtual media necessary for learning the physics-related phenomena are abstract and microscopic available. There are still many virtual media related material microscopic physics that have not been developed, such as the simulation of phase transition, a simulation of the mechanism of action of the batteries in 
electric circuits, simulation of conduction of heat, simulation of electrical resistance in the conductor, the simulation of the magnetism, the simulation of the propagation of sound waves in the air, a simulation of the Doppler effect, and others.

The concept construction in physics involves macroscopic (observable traits), and microscopic aspects (particles making up matter). Learning Physics mainly involving microscopic aspects would be less effective if presented by means of a lecture or class discussion without the support of the physical processesfor example, learning solid expansion, movement and distance related constituent particles (collisions between particles) and the temperature. This learning involves a dynamic aspect of particle motion may not be explained by drawing on the blackboard. When explained directly in front of the classes that just use the help whiteboard, learning is not effective because the study of the solid expansion involves microscopic dynamic aspect. This is what will lead to misconceptions experienced by learners.

Mastery of the basic concepts is still low by learners, one of which can lead to misconceptions. This is because the materials physics are microscopic so that learners are difficult to absorb the entire material well. Moreover, many basic concepts that require visualization that helps facilitate understanding of the concept of heat transfer.

A study was obtained that if the study only listened (lecture or teacher) without doing the other things such as notes, mastery of the material contributed by $5 \%$. Followed by reading, mastery of the material contributed by $10 \%$ and when studied with the help of audio visual mastery of the material contributed by $30 \%$ [3]. So that when the materials which are microscopic physics can be visualized using a media conception of physics, the construction can be constructed. This research aims at an overview of the characteristics of virtual media (MEVIAL) developed to study physics berorintasi construction on the scientific conception of matter which are microscopic.

\section{LITERATURE REVIEW}

\section{A. Dual Situated Learning Model (DSLM)}

In recent years, to promote students' scientific understanding and conceptual change, several researchers have attempted to develop instructional materials and researches for teaching of physics concepts: for example newton's law [17], optics [18], sound wave [19]. These researchers showed the importance of cognitive domain on learners' process of conceptual change toward better conceptual understanding. With the importance of studying pedagogical research and development in science learning, many instructional models were grounded on the theoretical aspects of conceptual change for several decades: for example, cooperative learning model, dual situated learning model (DSLM) [20], model-based inquiry; these models aim to introduce cognitive conflict structure and then allow them to adjust the existing conceptual.

With rapid growth of computers and technologies in a practice and progression of science education community, technology based approach to science learning offers computer simulation with opportunities for students' inquiry-related use.
Simulation-based-inquiry has been coming a pedagogical approach for enhancing students, conceptual learning in school science. The interacting with this approach, students practice scientific method in the context of performing their own investigations, while at the same time develop knowledge of the concept modeled by the simulation.

\section{B. Virtual Simulations in Physics Learning}

Computer simulations used for instructional purposes usually involve a model of a phenomena system with which the learner interacts. In such a context, learners construct their own knowledge by conducting experiments and by observing the effects of these experiments. Computer simulations have become increasingly dynamic and higher interactive over the last three decades and along with their multi-representation nature have gained a position along the tools of high educational value. Their positive impact to students' science learning has been confirmed through numerous studies.

Schools' widespread access to Information and Communications Technologies (ICT) pose tremendous challenges to physics teaching and learning. Physics is one of the first areas where the possibilities that computers may offer for the employment of new teaching methods have been and are still explored. A variety of computer applications have been developed and used in teaching Physics, such as spreadsheets [5], computer-based laboratories [4], multimedia [6], 1997; Wilson and Redish, [7], simulations [8], exploratory environments [9] and intelligent tutors [10]. Furthermore, research has often been employed to direct educational software design and development, as well as educational software evaluation. Among the various ICT applications, computer simulations are of special importance in Physics teaching and learning. Simulations offer new educational environments, which aim to enhance teachers' instructional potentialities and to facilitate students' active engagement. Computer simulations offer a great variety of opportunities for modeling concepts and processes. Simulations provide a bridge between students' prior knowledge and the learning of new physical concepts, helping students develop scientific understanding through an active reformulation of their misconceptions [11]. Specially, they are open learning environments that provide students with the opportunity to:

- develop their understanding about phenomena and physical laws through a process of hypothesis-making, and ideas testing;

- isolate and manipulate parameters and therefore helping them to develop an understanding of the relationships between physical concepts, variables and phenomena;

- employ a variety of representations (pictures, animation, graphs, vectors and numerical data displays) which are helpful in understanding the underlying concepts, relations and processes;

- express their representations and mental models about the physical world; and

- investigate phenomena which are difficult to experience in a classroom or lab setting because it is extremely 
complex, technically difficult or dangerous, moneyconsuming or time-consuming, or happen too fast.

We can distinguish between two types of computer models in physics [12]:

- exploratory models, which are constructed by experts to represent domain knowledge. Usually they are micro worlds that simulate physical processes and laws. Such micro-worlds encourage students explore and interact with them, handle parameters and observe their results; and

- expressive models, which allow students express their own ideas on a domain. They provide learners with tools to student relationships between concepts, explore the consequences of those student relationships and learn through an active process of representing their own models.

\section{Understanding of The Concepts (Consistency Conception)}

The consistency of conceptions of the students in this study includes the pattern of student answers using the same concept models in answering a series of questions asking the same concept. This data was obtained through the conception consistency test instruments tested one by asking questions with the same concept more than once.

Build the necessary concepts of harmony between the facts and the basic concepts owned learners so that the concept can be systematically awakened. However, alignment between the basic concepts owned learners are often influenced by the initial understanding obtained by learners before entering the class to obtain teaching under the guidance of a teacher. It is as stated by [2] stating that "Research of data collected over more than three Decades has shown that the majority of students come to science classes with pre-instructional knowledge or beliefs about phenomena and concepts to be taught ... ". The preliminary understanding is often at odds with the concept put forward by scientists. This condition is known as misconceptions (Alternative conceptions). As noted by [13] that "These students construct sensible and coherent understandings of phenomena and concepts as seen through Reviews their own eyes that do not match the views that are Universally accepted by the scientific community." Among the misconceptions found the matter waves is the sound wave propagation speed depends on the frequency of sound waves [14], the only wave interference is constructive, does not apply to the destructive [16], and sounds including transverse waves [15]. Various studies have tried to reveal misconceptions experienced by learners through open questions (open-ended questions), to explore the basic concepts used as an excuse by the students to answer questions. Development of the concept of measuring instruments (diagnostic instruments) continue to be made in order to document as many misconceptions experienced by learners in a variety of topics. This is done to prepare a study that is capable of changing misconceptions owned learners into appropriate understanding of the scientific conception, as expressed by Driver [16] that "... documenting all the alternative conceptions held by students Contribute to lecturers could "conceptual ability to effect change, as well as the benefits and inform science curriculum planning,
Generally". By knowing misconceptions owned learners, teachers can plan a learning process that is more planned and directed, in order to support the concept development process.

\section{METHODS}

\section{A. Research Design}

The purpose of the present study is to investigate the effects of simulation-based open inquiry with DSLM context on secondary school students, conceptual understanding, and conceptual change in physics. To broaden perspectives and understanding of the study phenomenon mentioned the mixed research methodology or mixed-method research with a combination qualitative of quantitative and research methodologies in a research study. The concurrent embedded strategy of the mixed research methodology was conducted by embedding qualitative research methodology within quantitative research methodology. For this study, phenomenological research methodology embedded one-group pre-, into post-, and retention quasi-experimental design, in which they addressed different research questions, as shown in Fig. 1.

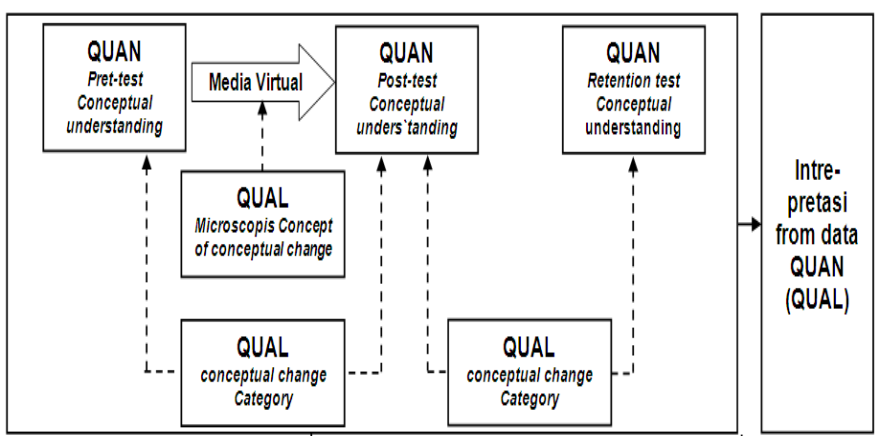

Fig. 1. Structure of research design of the study

\section{B. Study Participants}

A total of 30 student-respondents in their eleventh grade, age ranges from 18 to 21 years in Student of physics education, Indonesia University of Education. They were attending a physics course for basic education level. With an information interview with the regular class instructor before starting the experimental study, the result indicated to all of them have satisfactory skills on basic computer and information and communication, but they have no experience yet using a compute' simulation in physics. This research in the academic year 2014 \pm 2015 and took place about 4 months after students had received school teaching on thermal expansion of solids.

TABLE I. COMPONENTS OF SIMULATION-BASED OPEN INQUIRY WITH DUAL-SITUATED LEARNING MODEL TEACHING METHOD FOR STUDENTS CONCEPTUAL LEARNING IN BOUNDARY BEHAVIOR OF ON THERMAL EXPANSION OF SOLIDS AND ITS LEARNING PROCESS

\begin{tabular}{cc}
\hline $\begin{array}{c}\text { Components of } \\
\text { Simulation based open } \\
\text { inquiry }\end{array}$ & $\begin{array}{c}\text { Examples of Learning } \\
\text { Process }\end{array}$ \\
\hline Pre-lab & Teacher provides an open- \\
\hline
\end{tabular}


ended inquiry question:

What will happen if two

iron solid heat expansion?

Open-ended inquiry question Scientific background Information

Lab practice Procedure/design

Data and result analysis

Post-lab

Result communication

Conclusion
Teacher induces

collaborative discussion toward the definitions heat, heat transfer, and thermal expansion of solids

Students design their own scientific experiments and then interactive with

MVM simulation for collecting the experimental data for examples, by changing heat transfer of two solid different temperature

After tire interacting with simulation, students make a decision to analyze obtained experimental data from their own design and interpret it into results, for examples, calculation of arithmetic mean and standard deviation in order to use statistics for comparing the difference or use graphical charts for presenting the result Students have to select the way to present, communicate, and discuss the meaning of data and experimental results or others, for an example, writing experimental question, experimental design, results, and discussion on a new splint paper and then present to the class. In addition, they might use the MVM simulation in thermal expansion of solids Students have to collaboratively make a relationship between each group results and then draw it into a conclusion as the best answer to the provided inquiry question. For au example, teacher induces each group make a conclusive answer by using an integration of their own and other results

\section{RESULTS AND DISCUSSION}

\section{A. Development Media Virtual Microscopis.}

Virtual multimedia development stage that is done in this study included the analysis phase, the planning or design, production, and evaluation. Based on initial observations in the field indicate that some laboratories in schools has not been used optimally in the end a lot of teachers who rarely utilize the laboratory because it requires more energy to the preparation as well as for laboratory activities itself on the grounds there is no laboratory in the school that is felt appropriate that real lab created virtually. Analysis of the curriculum successfully selected thermal expansion of solids material with consideration of the material contains some abstract concept, so that very precise when made interactive multimedia that can simulate events that are difficult to observe by students and can simulate the thermal expansion of solids lab activities. In addition to these considerations, according to some teachers really matter physics, especially the material of thermal expansion of solids has a lot packed in the form of interactive multimedia both free and paid, but some teachers still was not satisfied because of interactive multimedia that is incomplete in terms of the content of the materials so that teachers should use a variety of sources for learning in the classroom, there are also many multimedia foreign language. Result it showed that the use of virtual media can change the conception of learners who have misconceptions through restructuring concept in depth [21] [22].

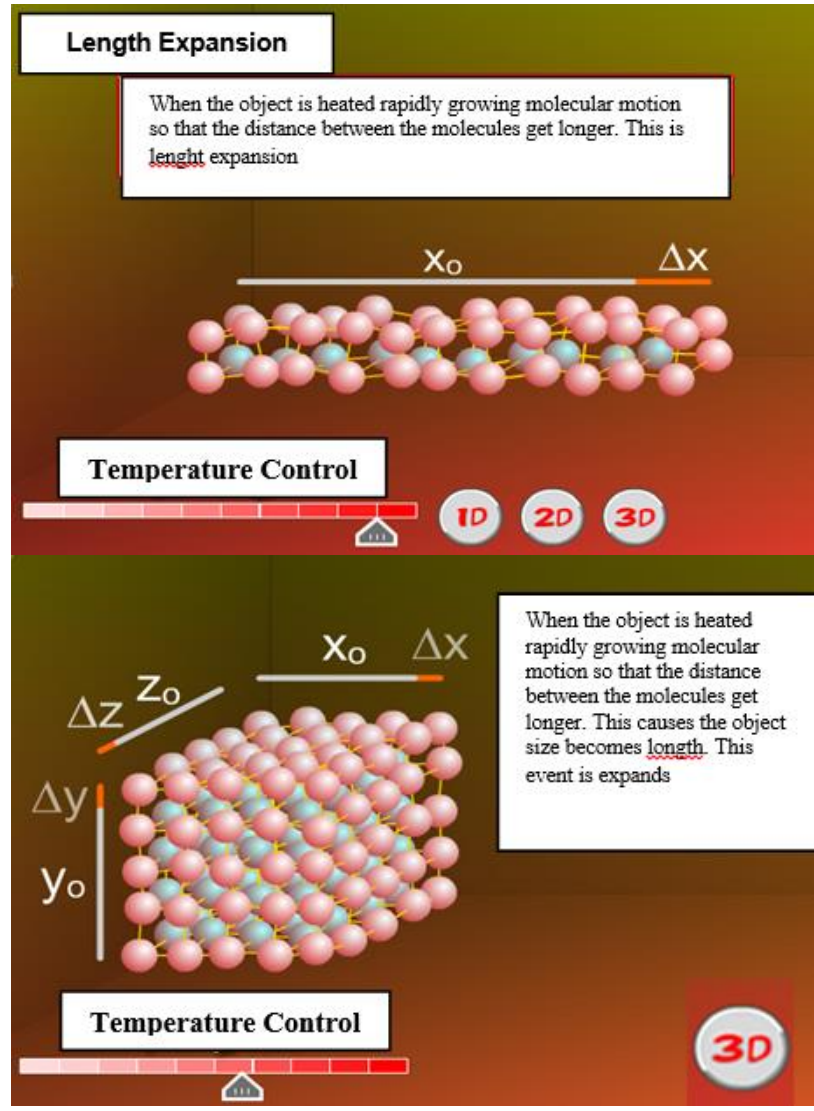

Fig. 2. Result Development of Microscopic Virtual Media (MVM) of Concept of Thermal Expansion of Solids 


\section{B. Analysis of Conceptual Understanding Score}

In order to explore the effects of the simulation-based open inquiry with DSLM on the students' conceptual development of thermal expansion of solids of statistical analysis using nonparametric test are shown in Table II.

TABLE II. STATISTICAL RESUlTS OF FRIEDMAN TEST AND, WILCOXON SIGN-RANKED TEST OF CONCEPTUAL UNDERSTANDING

\begin{tabular}{lccccc}
\hline $\begin{array}{c}\text { Test of } \\
\text { concept } \\
\text { understanding }\end{array}$ & $\begin{array}{c}\text { Mean } \\
(\mathbf{m a x} . \\
\mathbf{2 0})\end{array}$ & $\begin{array}{l}\text { Mean } \\
\text { Rank }\end{array}$ & SD & $\begin{array}{c}\text { Chi } \\
\text { square }\end{array}$ & $\begin{array}{c}\text { Post hoc } \\
\text { comparison }\end{array}$ \\
\hline (a) Pretest & 6.18 & 1.28 & 3.02 & $43.00^{*}$ & $($ b) $>($ a)* \\
(b) Posttest & 16.82 & 2.85 & 2.84 & & (b) $>($ c)* \\
(c) Retention & 10.65 & 2.48 & 2.95 & & (c) $>($ a)* \\
test & & & & &
\end{tabular}
$* \mathrm{P}<0.01$

The results are shown from Table II indicating that there was a statistically significant difference among overall pre-, post-, and retention-test scores of conceptual understanding on Thermal expansion, Chi square $=43.00, \mathrm{p}<0.01$. The result indicated also that the students' conceptual understanding showed significant improvement after simulating with the simulation-based open inquiry with MVM (from 6.18 to 16.82), but they made a slight decrease from posttest to retention test (from 16.82 to 10.65). Post hoc analysis with Wilcoxon signed rank test was conducted with correction applied, and the results indicated that the students mark a great progression of their conceptual understanding of thermal expansion of solid from pretest to posttest and the post test score was significant. The use of virtual simulation media could improve understanding of the concept and the process of changing the conception (Conceptual Change) students towards scientific conception [19].

The percentages of the quantity of conceptual change on the transitions of concept thermal expansion of solid presented in Fig. 3.

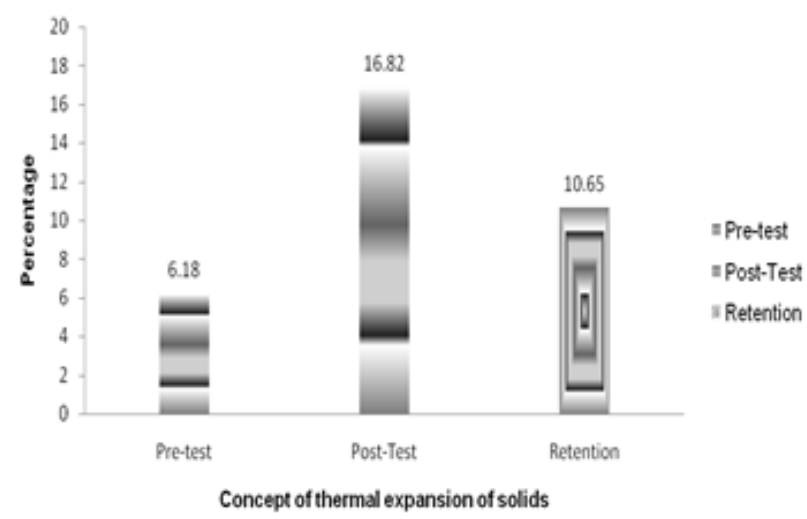

Fig. 3. Distribution of conceptual change conceptual change on the transitions of Concept Thermal Expansion

Based on the Fig. 3 obtained information that that students construct sensible and coherent understandings of phenomena and concepts as seen through Reviews their own eyes that do not match the views that are Universally accepted by the scientific community [13]. Media simulation is effective in helping students to construct its conception so that the ability to understand can be improved [25]. Use of virtual simulation media on the concept improve understanding of the concept of process of changing the conception (Conceptual Change) students towards scientific conception. Learning physics simulation that uses electric magnetic media can change the conception of a student who is not scientific to the scientific conception [26].

\section{CONCLUSIONS}

This study demonstrates how instructions using simulationbased open inquiry with DSLM trough these dual-situational learning events helped students successfully construct scientific understanding of concept thermal expansion phenomena. The results suggested that incorporation of learning by simulationbased open inquiry into DSLM has the potential for the development of students' conceptual understanding in science through the mechanical Process of conceptual change. Based on the results of research and discussion of the conclusions of this research are the results presented here show that students working with virtual media exhibited significantly higher scores. Our findings strongly support that MVM can be used as an alternative instructional tool, in order to help students confront reduce their scientific misconceptions and develop an understanding of physics concepts.

\section{REFERENCES}

[1] A. Suhandi and F. C. Wibowo. Approach Multirepresentasi In the Energy Work Learning and Impact on Student Concept Training. Jurnal Pendidikan Fisika Indonesia. 8 (1), pp. 1-7, 2012.

[2] R. Duit, and D. Treagust. Conceptual Change: A Powerfully Framework for Improving Science Teaching and Learning. International Journal of Science Education. 25, pp. 671-688, 2003

[3] The Higher Education Academy. Strategic Plan 2008-13. New York: The Higher Education Academy. 2008.

[4] R. K. Thornton and D. R. Sokoloff. Learning motion concepts using real-time microcomputer-based laboratory tools. American Journal of Physics, 58, pp. 858-867, 1990.

[5] R. A. Dory. Spreadsheets for physics. Computers in physics, May/Jun, pp. 70-74, 1988

[6] M. E. Crosby and M. K. Iding. The influence of a multimedia Physics tutor and user differences on the development of scientiffic knowledge. Computers and Education, 29, pp. 127-136, 1997.

[7] J. Wilson and F. Redish. The comprehensive unifield physics learning environment: part I. Background andfsystem operation. Computers in Physics, Mar/Apr, pp. 202-209, 1992.

[8] G. Andaloro, L. Bellomonte, and R. M. Sperandeo-Mineo,. A computerbased learning environment in the fieldf of Newtonian mechanics. International Journal of Science Education, 19, pp. 661-680, 1997.

[9] V. D. Teodoro. Learning with computer-based exploratory environments in Science and Mathematics. In S. Vosniadou, E. de Corte, and $\mathrm{H}$ Mandl, Technology-based learning environments, NATO ASI Series F, 137, pp. 26-32, 1993. Berlin: Springer-Verlag

[10] K. G. Schulze, R. N. Shelby, D. J. Treacy, and M. C. Wintersgill,. Andes: An active learning, intelligent tutoring system for Newtonian Physics. Themes in Education, 1(2), pp.115-136, 2000. 
[11] Jimoyiannis and Komis. Computer Simulations In Physics Teaching And Learning: A Case Study On Student's Understanding Of Trajectory Motion. Computers and Education 36, pp. 183-204, 2001.

[12] J. Bliss. Externalizing thinking through modeling: ESRC tools for exploratory learning research program. In S. Vosniadou, E. de Corte, R. Glaser, and H. Mandl, International perspectives on the design of technology-supported learning environments. pp. 25-40, 1996. New Jersey: Lawrence Erlbaum Associates.

[13] D. F. Treagust. Diagnostic Assessment in Science as a Means to Improving Teaching, Learning and Retention. UniServe Scence 2006 Conference Proceedings.

[14] A. Tongchai, M. D. Sharma, D. I. Johnston, K. Arayathanitkul and C. Soankwan. Consistency of Students' Conceptions of Wave Propagation : Findings From A Conceptual Survey in Mechanical Waves. Physical Review Special Topics-Physics Education Research, 7, pp. 020101, 2011.

[15] A. Tongchai, M. D. Sharma, D. I. Johnston, K. Arayathanitkul and C. Soankwan,. Students' Conceptual Knowledge of Mechanical Waves Across Different Backgrounds and Cultures. Symposium Proceedings: Visualisation and Concept Development, University of Sydney. UniServe Science Proceedings Visualisation, pp. 121-126, 2008.

[16] A. Coetzee, and S. N. Imenda. Alternative Conceptions Held by First Year Physics Students at A South African University of Technology Concerning Interference and Diffraction of Waves. Research in Higher Educational Journal, 1, pp. 1-13, 2012.

[17] Atasoy. S., \& Akdcmz, A. R. (2007). Developing and applying a tesis related to appearing misconceprions about Newtonian laws of motion. Journal of Turkish Science Education, 4 (1), pp. 45-50.

[18] Djanett, B. Fouad, C., \& Djamel, K. (2013). What Thinks' the University's Students about Propagarion of Light in the Vacuum? European Scientific Journal, 9 (24), pp. 197-213.

[19] Srisawasdi, N., \& Kroothkeaw, S. (2014). Supporting Students Conceptual Development of Light Refraction by Simulation-Based Open Inquiry with Dual-Situated Learning Model. Journal Computer \& Education, 1 (1), pp. 49-79.

[20] She, H. C., \& Liao, Y. W. (2010). Bridging Scientific Reasoning and Conceptual Change through Adaptive Web based Learning. Journal of Research in Science Teaching. 47 (1), pp. 91-119.

[21] She, H. C. (2003). DSLM Instructional Approach to Conceptual Change Involving Themal Expansion. Research in Science and Technological Edtcation, 21 (1), 43-54.

[22] She, H. C. (2004b). Fostering Radical Conceptual Change throught Dual-Situated Learning Model. Journal of Research in Science Teaching, 41 (2), 142-164.

[23] Mikropoulos. T. A.. \& Natsis, A. (2011). Educational Virtual Environments: A ten-year Review of Empirical Research (1999-2009). Journal Computers \& Education. 56, 769-780.

[24] Kaewkhong, K., Mazzolini, A., Narumon Emarat N., \& Arayathanitkul, C (2010). Thai High-School Students' Misconceptions about and Models of Light Refraction through a Planar Surface. Physics Education Journal, 45 (1), 91-101.

[25] Zacharias, Z., Olympiou, G., \& de Jong, T. (2013). Making the Invisible Visible: Enhancing Students' Conceptual Understanding by Introducing Representations of Abstract Objects in a Simulation. Instruction Science, 41, 575-596.

[26] Dega, B. G., Kriek, J., \& Mogese, T. F. (2013). Students' Conceptual Change in Electricity and Magnetismusing Simulations: A Comparison of Cognitive Perturbation and Cognitive Conflict. Journal of Research in Science Teaching, 50 (6), 677-699.G. Eason, B. Noble, and I.N. Sneddon, "On certain integrals of Lipschitz-Hankel type involving products of Bessel functions," Phil. Trans. Roy. Soc. London, vol. A247, pp. 529-551, April 1955. (references) 